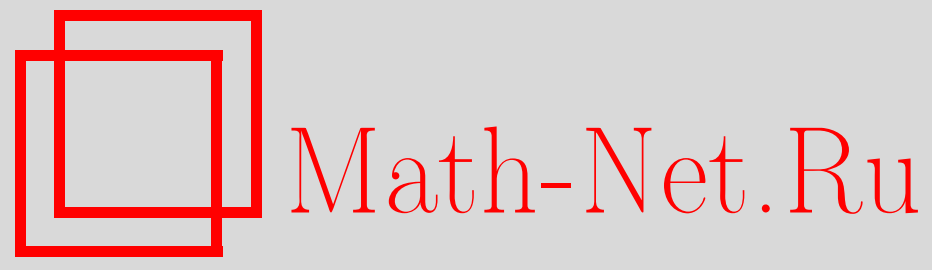

А. Д. Васильев, Влияние плотности дислокаций в никеле и железе на кинетику анодного процесса в хлористом электролите, Вестн. Сам. гос. техн. ун-та. Сер. Физ.-мат. науки, 2012, выпуск 3(), 208-210

DOI: https://doi.org/10.14498/vsgtu1096

Использование Общероссийского математического портала Math-Net.Ru подразумевает, что вы прочитали и согласны с пользовательским соглашением

http://www.mathnet.ru/rus/agreement

Параметры загрузки:

IP: 54.80 .97 .219

26 апреля 2023 г., 11:50:51

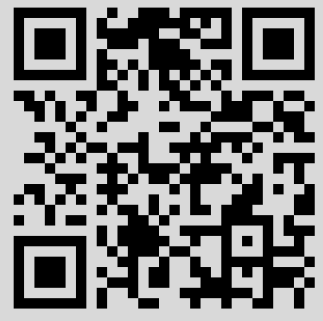


Вестн. Сам. гос. техн. ун-та. Сер. Физ.-мат. науки. 2012. № 3 (28). С. $208-210$

Физика твёрдого тела

УДК 539.219; 541.135

\title{
ВЛИЯНИЕ ПЛОТНОСТИ ДИСЛОКАЦИЙ В НИКЕЛЕ И ЖЕЛЕЗЕ НА КИНЕТИКУ АНОДНОГО ПРОЦЕССА В ХЛОРИСТОМ ЭЛЕКТРОЛИТЕ
}

\author{
А. Д. Василъев \\ Самарский государственный технический университет, \\ 443100, Россия, Самара, ул. Молодогвардейская, 244. \\ E-mail: vasilyevad@mail.ru
}

\begin{abstract}
Исследовалось влияние плотности дислокаций в аноде на плотность анодного тока для железа (сталь 10) и никеля в хлористом электролите. Для создания в материале анода повышенной плотности дислокаций этот материал механически деформировался на $15 \%$. Обнаружено, что с ростом плотности дислокачий примерно на порядок плотность анодного тока увеличивается в несколько раз. Наблюдалось увеличение неравномерности растворения никелевого анода при увеличении в нем плотности дислокаций.
\end{abstract}

Ключевые слова: плотность дислокаций, плотность анодного тока.

Введение. Во время исследования кинетики электрохимических процессов обычно не указывают структуру электродов с точки зрения наличия в них дефектов кристаллической решётки. Однако достаточно хорошо известно, что в областях, в которых дислокации выходят на поверхность электродов, электрохимические процессы протекают более активно [1]. Вместе с тем в литературе практически отсутствуют экспериментальные данные о количественном влиянии плотности дислокаций в электродах на кинетику электрохимических процессов. В работе [2] приведены такие результаты для медных электродов, находящихся в сернокислом электролите. Однако по ряду соображений следует, что для электродов из подгруппы железа это влияние будет более сильным.

Растворение анода - сложный, многостадийный процесс. Очевидно, что дислокации должны влиять только на те процессы, которые происходят непосредственно на аноде. Электролит имеет аморфную структуру, и вряд ли его структура меняется вблизи выхода дислокации на поверхность анода. Поэтому дислокации должны сильно влиять на кинетику анодного растворения тех металлов, у которых затруднен отрыв ионов от кристаллической решетки при его переходе из анода в электролит, то есть у металлов с минимальным током обмена, например, у металлов подгруппы железа. Данное предположение было экспериментально проверено на железе и на никеле.

Методика эксперимента. В качестве железных анодов использовалась сталь 10 , для никелевых применялся технически чистый никель $(99,99 \% \mathrm{Ni})$.

Использовался электролит, содержащий 0,5 $\mathrm{M} \mathrm{H}_{2} \mathrm{SO}_{4}$ и 0,5 M NaCl. Эксперименты с использованием никелевых и железных анодов проводились следующим образом. В электролитическую ячейку помещались один катод и два анода, по которым одновременно протекали токи: один анод с высокой плотностью дефектов кристаллической решётки, другой - с низкой. В качестве первого типа анодов использовались железо или никель, продеформированные на $15 \%$. В качестве анодов

Алексей Дмитриевич Васильев (д.ф.-м.н., проф.), профессор, каф. общей физики и физики нефтегазового производства. 
с низкой плотностью дефектов решётки применялись образцы, отожжённые при температуре $800^{\circ} \mathrm{C}$ в вакууме в течение 0,5 ч. Оба анода имели одинаковый потенциал, который измерялся с помощью хлорсеребряного электрода. Ток каждого анода измерялся отдельным амперметром. Для того чтобы растравливание анода не сильно меняло их площадь в процессе эксперимента, выдержка на каждом режиме составляла примерно одну минуту. Плотность дислокаций в металлах измерялась рентгенографическим методом по уширению дифракционных линий [3].

Результаты экспериментов и их обсуждение. Результаты экспериментов представлены в табл. 1 и 2 для никеля и железа соответственно. Потенциалы анодов приведены по водородной шкале. Из приведенных данных видно, что плотность дислокаций достаточно сильно влияет на плотность анодного тока, который может меняться в несколько раз. Это подтверждает предположение, что в группе железа дефекты решётки влияют на плотность анодного тока сильнее, чем в меди.

Следует отметить, что в экспериментальных работах очень редко в деталях указывают структуру электродов, участвующих в электрохимических процессах. Обычно это делается при использовании монокристаллических электродов. Часто об этой структуре ничего не сообщается. Однако из данных, приведенных в настоящей статье, следует, что при изучении электродной кинетики крайне желательно сообщать информацию о структуре электродов, участвующих в электрохимических процессах.

В никеле помимо количественного влияния плотности дислокаций на электроТаблица 1

Значения плотности анодного тока в никеле при различной плотности дислокаций в никелевом аноде

\begin{tabular}{|c|c|c|}
\hline \multicolumn{2}{|c|}{ Плотность анодного тока, $\mathrm{A} / \mathrm{cm}^{2}$} & \multirow{2}{*}{$\begin{array}{c}\text { Потен- } \\
\text { циал } \\
\text { анода, В }\end{array}$} \\
\hline $\begin{array}{l}\text { Плотность дислока- } \\
\text { ций в аноде } 10^{9} \mathrm{~cm}^{-2}\end{array}$ & $\begin{array}{c}\text { Плотность дислока- } \\
\text { ций в аноде } 10^{10} \mathrm{~cm}^{-2}\end{array}$ & \\
\hline $0,4 \cdot 10^{-3}$ & $1,5 \cdot 10^{-3}$ & 0,23 \\
\hline $1,5 \cdot 10^{-3}$ & $4,5 \cdot 10^{-3}$ & 0,24 \\
\hline $5 \cdot 10^{-3}$ & $10 \cdot 10^{-3}$ & 0,25 \\
\hline
\end{tabular}

Таблица 2

Значения плотности анодного тока в железе (сталь 10) при различной плотности дислокаций в железном аноде

\begin{tabular}{|c|c|c|}
\hline \multicolumn{2}{|c|}{ Плотность анодного тока, $\mathrm{A} / \mathrm{cm}^{2}$} & \multirow{2}{*}{$\begin{array}{c}\text { Потен- } \\
\text { циал } \\
\text { анода, В }\end{array}$} \\
\hline $\begin{array}{l}\text { Плотность дислока- } \\
\text { ций в аноде } 10^{9} \mathrm{~cm}^{-2}\end{array}$ & $\begin{array}{c}\text { Плотность дислока- } \\
\text { ций в аноде } 10^{10} \mathrm{~cm}^{-2}\end{array}$ & \\
\hline $0,05 \cdot 10^{-3}$ & $0,1 \cdot 10^{-3}$ & $-0,15$ \\
\hline $1 \cdot 10^{-3}$ & $9 \cdot 10^{-3}$ & $-0,06$ \\
\hline $5 \cdot 10^{-3}$ & $20 \cdot 10^{-3}$ & 0,07 \\
\hline
\end{tabular}

химический процесс было замечено и качественное влияние. Если электролиз проводить более 0,5 ч, то становилось заметным следующее обстоятельство. Отожженный никелевый анод растравливался достаточно равномерно по всей площади электрода. А у деформированного никелевого анода этот процесс протекал крайне неоднородно. На поверхности электрода были видны области, где глубина, на которую растворился никелевый анод, в разы превышала среднюю величину. Скорее всего, это связано с тем, что пластическая деформация часто протекает крайне неравномерно, а это приводит к неравномерному распределению дефектов кристаллической решетки в образце, следствием чего и является неравномерное растворение никелевого анода. Отжиг приводит к уменьшению плотности дислокаций и к их более равномерному распределению в никелевом образце, что и обуславливает выравнивание скорости электрохимического процесса вдоль поверхности анода.

Выводы. Таким образом, экспериментально установлено влияние плотности дислокаций в медном аноде на кинетику анодного процесса в сернокислом электролите и зависимость плотности анодных токов на никелевых и железных анодах в кислом хлоридном электролите от дефектной структуры этих анодов. Во всех случаях возрастание плотности дислокаций в материалах электродов приводит к росту анодного тока. 


\section{БИБЛИОГРАФИЧЕСКИЙ СПИСОК}

1. Дамаскин Б. Б., Петрий О. А., Цирлина Г. А. Электрохимия. М.: Колосс-Химия, 2006. 672 c. [Damaskin B. B., Petriy O.A., Tsirlina G.A. Electrochemistry. Moscow: KolossKhimiya, 2006. 672 pp.]

2. Васильев А.Д., Косулин С.И., Балакиров С.Н. Влияние плотности дислокаций медного электрода на кинетику анодного процесса в сернокислом электролите // Becmн. Сам. гос. техн. ун-та. Сер. Физ.-мат. науки, 2010. №5(21). C. 302-304. [Vasil'ev A. D., Kosulin S.I., Balakirov S.N. Influence of dislocation density of copper electrode on the kinetics of anode process in acidic $\mathrm{CuSO}_{4}$ solution // Vestn. Samar. Gos. Tekhn. Univ. Ser. Fiz.-Mat. Nauki, 2010. no. 5(21). Pp. 302-304].

3. Иверонова В.И., Ревкевич Г.Г. Теория рассеивания рентгеновских лучей. М.: МГУ, 1978. 276 c. [Iveronova V.I., Revkevich G.P. Theory of X-ray Scattering. Moscow: Mosk. Gos. Univ., 1978. 276 pp.]

Поступила в редакцию 13/VI/2012;

в окончательном варианте - 22/VII/2012.

MSC: 74N15; 74-05

\section{INFLUENCE OF DENSITY OF DISLOCATIONS IN NI AND FE ON KINETICS OF ANODE PROCESS IN CHLORIDE ELECTROLYTE}

\section{A.D. Vasilyev}

Samara State Technical University,

244, Molodogvardeyskaya st., Samara, 443100, Russia.

E-mail: vasilyevad@mail.ru

Influence of density of dislocations in Ni and Fe on kinetics of anode process in chloride electrolyte was studied. To create the increased density of dislocation this material was deformed by $15 \%$. It was discovered that the density of anode current increases several times with the increase of the density of dislocation. It was observed that the unevenness of dissolution of Ni anode increases with the increase of the density of dislocations in it.

Key words: density of dislocations, density of current in anode.

Original article submitted 13/VI/2012; revision submitted 22/VII/2012.

Alexey D. Vasil'ev (Dr. Sci. (Phys. \& Math.)), Professor, Dept. of General Physics. 